\title{
O EXPERIMENTO BAYLE: FORMA FILOSÓFICA, CETICISMO, CRENÇA E CONFIGURAÇÃO DO MUNDO HUMANO
}

\author{
Renato Lessa* \\ rlessa@iuperj.br
}

RESUMO Oartigo tem por objetivo principal definir o que designa como o Experimento Bayle. Bayle praticou uma forma narrativa aberta, construida como diálogo do autor com seus personagens, e marcada pela recusa de um espírito geométrico. Tal recusa formal da geometrização, por seu lado, é fundamental para o desenvolvimento, em Bayle, de uma percepção da história e da política como domínios constituídos por uma miríade incontável de ações humanas fundadas sobre paixões e crenças. $O$ artigo tenta buscar alguns traços dessa percepção entre os textos dedicados por Bayle a Maquiavel, Bodin e Hobbes, no seu Dicionário, assim como nas críticas dirigidas por Montesquieu a Bayle, a propósito do ateísmo e da desvalorização moral do cristianismo.

Palavras-chave forma filosófica, ceticismo, crença.

RÉSUMÉ L'article a pour but principal la définition de ce qu'il désigne comme l'Expériment Bayle. Bayle a pratiqué une forme narrative ouverte, construite comme dialogue de l'auteur avec ses personnages, et marquée par le refus d'un esprit géométrique. Ce refus formel de la géométrisation, à son côté, est fondamental pour le développement chez Bayle d'une perception de l'histoire et de la politique comme domaines constitué par une

* luperj/Universidade Federal Fluminense/CNPq, Rio de Janeiro. Artigo recebido em 18/10/2009 e aceito em 06/11/2009.

KRITERION, Belo Horizonte, no 120, Dez./2009, p. 461-475. 
myriade incomptable des actions humaines fondées sur les passions et les croyances. L'article essaie de trouver quelques traites de cette perception parmi les textes qui Bayle a écris au sujet de Machiavelli, Bodin et Hobbes dans son Dictionnaire, aussi bien que dans les critiques adressés a Bayle pour Montesquieu, au sujet de l'athéisme et de la dévalorisation moral du christianisme.

Mots clés forme philosophique, scepticisme, croyance

\section{Da forma Bayle}

Começo por considerar o que pode ser designado como a forma Bayle. Thomas Lennon, em seu livro introdutório a respeito de Pierre Bayle, indicou algumas características centrais do experimento bayleano do Dictionnaire. ${ }^{1}$ Todas elas podem ser apresentadas pela interposição do termo forma: (i) presença de uma forma de explanação de caráter narrativo; (ii) uma forma de exercício filosófico na qual ocorre uma identidade entre filosofia e história da filosofia; (iii) uma aproximação entre as formas narrativas da história e da filosofia - e destas com a da ficção literária; (iv) uma forma de filosofia construída como diálogo.

Tais traços constituem os marcadores mais gerais do que aqui pode ser designado como a forma Bayle. Uma forma de filosofia que, contudo, exige, para que produza efeitos textuais visíveis, a ação de alguns operadores, que podem ser definidos, ainda a utilizar três fórmulas propostas por Lennon, como independence of voice, personalized conscience e open-endedness. ${ }^{2}$ Os dois últimos desses operadores - personalized conscience e open-endedness - dizem, respectivamente, do caráter pessoal do próprio texto bayleano e de seu aspecto aberto e de não-terminalidade. Ambos são fundamentais para a consideração do enigma Bayle. ${ }^{3}$ Gostaria, no entanto, de por sob foco mais preciso o que parece estar sob inspeção no primeiro operador, designado como independence of voice. Nos termos de Lennon, independence of voice is the notion that characters speak for themselves, not as authorial mouthpieces. ${ }^{4}$

1 Thomas Lennon, Reading Bayle, Toronto: University of Toronto Press, 1999, pp. 24-28.

2 Ibidem, pp. 31-41.

3 Para Ruth Whelan, Bayle "is surely the most misunderstood writer of his age", Cf. Ruth Whelan, The Anatomy of Superstition: A Study of the Historical Theory and Practice of Pierre Bayle, Oxford: Oxford University Press, 1989, p. 9. Thomas Lennon aponta para o fato de que não se trata de um enigma que decorra de uma multiplicidade de interpretações, mas simplesmente da dificuldade de fixar nele uma estrutura argumentativa. Cf. Thomas Lennon, op. cit., p. 15. 
Um texto marcado pela presença de tal voz independente deve possuir características estruturais que o distinguem de narrativas monológicas. A forma Bayle constitui-se por oposição às seguintes características, típicas das narrativas monológicas: objetividade, literalidade, fixidez, encerramento, impessoalidade e persecução da verdade como objetivo maior. Na verdade, é de uma forma de pensamento, mais do que de um estilo narrativo, que estamos a falar. Dois aspectos podem ser aqui considerados, pois permitem a passagem da forma textual para a forma do pensamento.

$\mathrm{O}$ primeiro deles diz respeito ao cariz histórico do empreendimento bayleano. O cético, em Bayle, como notou José Raimundo Maia Neto é "essencialmente um historiador". ${ }^{5}$ Seu caráter pode ser depreendido através de uma distinção estabelecida por Bayle entre dois tipos de filosofia, praticadas respectivamente pelos avocats e pelos rapporteur. ${ }^{6}$

A Antiguidade conheceu dois tipos de filósofos, alguns agiam como advogados e outros como aqueles que reportam uma causa. Os primeiros [avocats] quando expõem suas opiniões, escondem tanto quanto podem o lado fraco de sua causa e o lado forte dos adversários. Os últimos [rapporteurs]... ,os céticos e acadêmicos, apresentavam fielmente, sem qualquer parcialidade, os argumentos fracos e fortes das partes em conflito. ${ }^{7}$

A distinção indica ainda o caráter necessariamente local e finito do rapporteur. Trata-se de um observador constituído por circunstâncias particulares, em um eco visível do Quarto Tropo de Enesidemo ${ }^{8}$ ao qual se junta uma inevitável aproximação com o historikós sextiano.

$\mathrm{O}$ segundo aspecto diz respeito à oposição de Bayle a paradigmas que pressupõem a presença e a ação de operadores de infinito - para aqui introduzir a terminologia e o problema postos por Fernando Gil. ${ }^{9}$ Tais operadores procedem por meio de uma precipitação da razão na existência, pela qual toda contingência e toda variedade cedem diante do ânimo geométrico. No lugar de operadores de infinito, deparar-nos-emos em Bayle com a presença de operadores de circunstância, de circunscrição e de finitude. Tais operadores estão necessariamente limitados pelo espaço e pelo tempo. A crença no ilimitado

5 Cf. José Raimundo Maia Neto, "O ceticismo de Bayle", Kriterion, 93, 1995, p. 86.

6 Sobre essa distinção ver o artigo mencionado de José Raimundo Maia Neto, Kriterion, 93, 1995, pp. 7788.

7 Cf. Pierre Bayle, Nota G, do artigo sobre Crisipo, Dicionário Histórico e Crítico, apud Maia Neto, op. cit. Pp. 84-85.

8 Cf. Sexto Empírico, HP, I, 101.

9 Cf. Fernando Gil, A Convicção, Porto: Campo das Letras, 2003, esp. $2^{a}$ parte: "O pensamento soberano", pp. 93-170. 
cede lugar à crença no limite e na circunscrição. ${ }^{10} \mathrm{O}$ peso da contingência em Bayle foi captado por Elisabeth Labrousse, em belo comentário no qual se refere àquele autor como tomado por um amour du concret qui le tourne avec prédilection vers le contingent par excellence. ${ }^{11}$

A orientação para o que é circunscrito e particular tem como efeito a interpelação ativa das pretensões de universalidade e do espírito geométrico. Tal interpelação exige daquele que afirma o fundamento universal de todas as coisas a apresentação das fundações particulares do seu saber. À crença dogmática no fundamento, o ceticismo presente em Bayle opõe um regime de crença natural no mundo tal como ele se apresenta: um domínio constituído por incontável variedade de circunstâncias, um tema que já se apresentara em Montaigne. O observador constituído por essa crença básica - natural animal faith, nos termos de Popkin ${ }^{12}$ - quando emite juízos sobre o mundo, o faz movido por uma perspectiva de circunscrição, limite e irresolução. ${ }^{13}$ Os operadores de circunscrição - que decorrem do imperativo da circunstância - são, ao mesmo tempo, operadores de irresolução. A precipitação no abismo dos fenômenos, sem o socorro da crença nos fundamentos, tem parte com a afirmação dos limites do sujeito e de sua irresolução.

Seriam tais características de ordem puramente narrativa e formal? Em parte sim, posto que são dimensões, mais do que irrecorríveis, necessárias à fabulação filosófica. No entanto, gostaria de considerar a co-presença de um conjunto de definições substantivas, sem incorrer na ingenuidade de supor serem os problemas de natureza substantiva anteriores à sua formalização narrativa. De modo mais direto, em Bayle impõe-se um nexo indissolúvel entre forma e conteúdo: trata-se uma forma que só pode apreender os problemas que comporta; trata-se, ainda, de uma substância - ou conjunto de problemas - que só pode ser constituída e revelada pela forma particular que a apresenta.

Em outros termos, há dimensões substantivas fortes que exigem a própria forma pela qual são consideradas. Do ponto de vista desta reflexão, três delas devem aqui ser consideradas:

(i) uma perspectiva não geométrica na interpretação da história;

10 Tratei do tema dos operadores céticos de circunscrição no ensaio "Montaigne's and Bayle's Variations: The Philosophical Form of Scepticism in Politics”, In: J. R. Maia Neto, J. C. Laursen e G. Paganini (Eds.), Skepticism in Modern Age: Building on the work of Richard Popkin, Leiden: Brill, 2009. O texto está também disponível em http://www.estudoshumeanos.com/pdf/the-philosophical-form.pdf.

11 Cf. Élisabeth Labrousse, Pierre Bayle, Paris: Albin Michel, 1996, p. 5.

12 Cf. Richard Popkin, "Pierre Bayle's place in the $17^{\text {th }}$ century", In: Paul Dibon, op. cit., p. 15.

13 Para a relação entre ceticismo e irresolução, a referência obrigatória é o livro de Silvia Giocanti, Penser I'Irrésolution: Montaigne, Pascal, La Mothe Le Vayer. Trois itinéraires sceptiques, Paris, Honoré Champion, 2001. 
(ii) o tratamento do tema da crença na configuração da vida social;

(iii) a não-terminalidade do experimento humano.

Proponho-me, a seguir, a desenvolver um experimento. Trata-se de - a partir das referências de Bayle a Maquiavel, Bodin e Hobbes, no contexto do Dicionário, e do modo pelo qual foi recepcionado por Montesquieu, no início do séc. XVIII - constituir um mundo bayleano no qual as dimensões acima indicadas têm lugar de destaque.

\section{Bayle leitor de Maquiavel, Bodin e Hobbes}

Parto aqui de um comentário sugestivo, feito por Sally Jenkinson, na Introdução ao volume Bayle, da série de clássicos do pensamento político, editada pela Cambridge University Press. O comentário sugere a necessidade de reinterpretar Bayle, como analista do pensamento e da prática da política, em diálogo com os grandes pensadores da modernidade, tais como Maquiavel, Bodin e Hobbes, e como protagonista de uma teoria política da diversidade. ${ }^{14}$

Jenkinson, contudo, não tira proveito de seu ótimo insight. Presa ao contextualismo cambridgeano, trata, sob a promissora rubrica "The political ideas which Bayle opposed", apenas de tendências políticas e ideológicas correntes naquela quadra histórica: gallicanistas, huguenotes, politiques, ultramontanos. O material que acabou por editar - composto por verbetes "políticos" do Dictionnaire, revela, no entanto, afinidades e aversões bayleanas para além das marcas da conjuntura imediata. É certo que Bayle, pensador por excelência das circunstâncias, considera de forma atenta as vertentes que configuram o campo político imediato. Seu argumento a respeito da tolerância, por exemplo, assim o exige. No entanto, a intervenção de Bayle - tal como o havia sido, em direção diversa, a de Espinosa - parece ser de natureza filosófico-política. Quer isso dizer que incide sobre um campo mais amplo do que o da política imediata e é por meio dessa intervenção que o encontramos a falar de Maquiavel, Bodin e Hobbes.

1. No verbete do Dicionário a respeito de Maquiavel, Bayle não disfarça sua admiração, tanto no que diz respeito ao realismo político quanto à perspectiva não-geométrica do secretário florentino ${ }^{15}$. Apesar de reconhecer que 
"não há muitos autores que sobre ele escrevem sem tentar denegrir sua memória", Bayle sugere uma linha de defesa:

Se os seus motivos são assunto controverso, deve-se, no mínimo, reconhecer que em sua conduta ele apresentou-se como inspirado de modo formidável no espírito do republicanismo. ${ }^{16}$

Bayle reage aos críticos de Maquiavel, com menção especial ao Padre Lucchesini que, em 1697, fez publicar em Roma um livro com o sugestivo título de Saggio della sciocchezza di Nicolò Machiavelli. Na seqüência, apresenta sua hipótese maior a respeito do sentido principal do Príncipe, por meio de uma citação do "autor das Nouvelles de la Republique des Lettres" (o próprio Bayle):

É surpreendente que haja tão poucos que contestem que Maquiavel sugira aos príncipes uma política perigosa, dado que, ao contrário, são os príncipes que impõem a Maquiavel tudo o que ele escreveu. Seus mestres foram o estudo do mundo e a observação de desdobramentos reais, e não uma imaginosa meditação pessoal. ${ }^{17}$

$\mathrm{Na}$ defesa de Maquiavel, a adesão a um argumento de realismo político: o pecado, "no caso dos soberanos, sem ser desculpável, é necessário". No entanto, cabe a reserva, não são poucos os que se contentam com o que é necessário: "eles não estariam nessa ruinosa condição de necessidade se fossem todos homens decentes". ${ }^{18} \mathrm{O}$ exercício da política é instrutivo: por meio dele "os mais inocentes aprenderiam a ser repreensíveis, através do simples exercício da realeza e sem a necessidade de qualquer tutor". ${ }^{19}$ Bayle, ao falar de Maquiavel, aceita um princípio de mecânica ou de automatismo da maldade: não é necessário que o príncipe seja mau ou imoral. São antes as contingências da política que impõem sua lógica própria. Há, pois, uma dimensão fática e irrecusável que estabelece a sua própria evidência.

O mérito de Maquiavel teria sido, portanto, o de revelar uma fenomenologia da política antes encoberta por representações e imagens inadequadas. Um dos comentadores mobilizados por Bayle, para defesa do autor do Príncipe, o republicano Trajano Boccalini, em seu Ragguagli di Parnasso, "com grande sutileza sugere que Maquiavel aprendeu o que significa a política 
em seu Príncipe com o reinado de certos papas". ${ }^{20}$ A menção a Boccalini é importante, um dos argumentos básicos de Bayle a respeito de Maquiavel - o de seu mimetismo - parece ter sido dele diretamente retirado.

Bayle prossegue com o argumento Boccalini: se o que escreveu Maquiavel decorre de doutrina própria, de sua própria invenção, que sobrevenha merecida sentença; se, ao contrário, o que escreveu decorre da observação das ações de certos príncipes, porque razão seria condenado como ateu ou calhorda e seriam os autores reais dos fatos execráveis considerados inocentes? "Que razão há para que um original seja tomado como sagrado e sua cópia queimada como ímpia e execrável?’’1

Há, contudo, um perigo em Maquiavel, diz-nos Bayle, que decorre do que poderia ser aqui designado como seu mimetismo político: "É incontestável, no entanto que a leitura da história incidentalmente produz de modo preciso o mesmo efeito produzido pela leitura de Maquiavel". ${ }^{22} \mathrm{O}$ cuidado na leitura de Maquiavel não exige a refutação de suas observações, mas a atenta percepção da perspectiva a partir da qual foram construídas.

O reconhecimento do realismo político de Maquiavel constitui para Bayle um aspecto de sua perspectiva mais ampla de interpretação da vida social. Para Maquiavel o realismo impõe-se pela imparável atividade humana em sua obsessão por melhorar. A diversidade das ações humanas configura um cenário potencial de desordem, que acaba por exigir a ação ordenadora do soberano. Uma ação que decorre da contingência da variedade humana, sendo ela mesma contingente. Bayle, com grande probabilidade, admirou em Maquiavel a ausência do espírito de geômetra ou de uma vontade de sistema. ${ }^{23}$ O trânsito bayleano para um realismo mais amplo, de natureza sociológica, pode ser atestado em seguinte passagem dos Pensamentos Diversos sobre o Cometa, na qual o autor fornece conselhos para nações que desejam riqueza e poder: manter a avareza e a ambição "em todo o seu ardor", premiar os que inventam manufaturas e desenvolvem o comércio, "não temer os efeitos do amor pelo ouro". As desordens que assaltaram os romanos pela cobiça por ouro não são razões para preocupação: "não é necessário que as mesmas coisas aconteçam em todas épocas e sob climas diferentes". O desfecho: "Você conhece a máxima de que um homem desonesto é capaz de ser um

20 Ibidem, p. 165.

21 Ibidem, p. 166.

22 Ibidem, p. 166.

23 O termo vontade de sistema foi cunhado por Diogo Pires Aurélio, em seu livro sobre Descartes, Hobbes e Espinosa, A vontade de sistema: estudos sobre filosofia e política, Lisboa : Cosmos, 1998. 
bom cidadão. Ele proporciona serviços que um homem honesto é incapaz de executar". ${ }^{24}$

2. Consideremos, agora e de modo mais breve, o verbete do Dicionário dedicado a Jean Bodin. ${ }^{25}$ Para Bayle, Bodin foi "um dos franceses mais inteligentes do século XVI". Ao contrário do que a legenda absolutista de Bodin poderia supor, o que sobrevém do relato de Bayle põe em relevo dimensões distintas. Na nota I do verbete dedicado a Bodin, por exemplo, Bayle afirma que em pelo menos uma ocasião - nos États de Blois - Bodin "teria demonstrado boa vontade com relação aos direitos do povo". ${ }^{26} \mathrm{O}$ ângulo de Bayle privilegia o tema da tolerância religiosa e não o de uma reflexão a respeito da soberania. Bodin surge nesse quadro menos como um autor devotado ao tema da soberania e mais como alguém preocupado com o papel que esta cumpre no que diz respeito à liberdade religiosa. Dessa forma, Bayle qualifica o comportamento de Bodin em Blois: ele "teve a coragem de opor-se aos que queriam que todos os súditos do rei fossem compelidos a professar a religião católica (pois) tal resolução configuraria uma infração dos Editos". ${ }^{27}$ Bodin, segundo Bayle, teria afirmado que às seitas religiosas deveria ser garantida a liberdade de consciência.

Com relação ao tema central de Bodin - o da soberania - Bayle aponta o que define como inconsistência daquele pensador. Ao mesmo tempo em que Bodin "falou de forma direta contra os que mantêm que a autoridade real é ilimitada ... falhou em satisfazer os que têm sentimentos republicanos". ${ }^{28}$ A razão disso teria sido a crença de Bodin de que "não é apropriado aos súditos conspirar contra a vida e contra a honra dos monarcas, tanto por meios violentos como por meios judiciais, mesmo que tenham cometido toda vilania, impiedade e crueldade que possam ser nomeadas". ${ }^{29}$

Realismo político e tolerância combinam-se na avaliação de Bodin feita por Bayle. A recepção bayleana de certa ilimitação do poder parece regulada pela percepção de que esta é mesmo uma garantia para a liberdade religiosa. Trata-se, pois, de quebrar o vínculo entre soberania ilimitada e homogeneidade em matéria de crença e culto religiosos.

24 Cf. Pierre Bayle, Pensés Diverses sur la Comète, apud Thomas Horne, The Social Thought of Bernard Mandeville: Virtue and Commerce in Early Eigtheenth Century England, London: The Macmillan Press, 1979, pp. 30-31.

25 Cf. Pierre Bayle, “Bodin”, In: Sally L. Jenkinson (Ed.), op. cit., pp. 17-28.

26 Ibidem, p. 20.

27 Ibidem, pp. 18-19.

28 Ibidem, p.10.

29 Ibidem, p. 20. 
3. Na nota $\mathrm{E}$ de seu verbete sobre Hobbes, ${ }^{30}$ Bayle considera a recepção do De Cive: "A obra proporcionou a Hobbes muitos inimigos, mas ele obriga os que possuem visão mais larga a admitir que os fundamentos da política jamais haviam sido tão bem analisados". ${ }^{31}$ No entanto, Hobbes teria levado as coisas "longe demais". ${ }^{32}$ Em sua oposição aos adeptos do parlamento, Hobbes teria optado por uma posição extremada ao postular que a autoridade dos reis não deve ter limites e que os aspectos exteriores da religião, causa mais virulenta da guerra civil, deve depender de sua vontade". ${ }^{33}$

A distinção de fundo é, contudo, de outra natureza. Não são as injunções políticas da obra hobbesiana que importam a Bayle, e sim o modo pelo qual constrói o seu sistema. O problema de Hobbes é o da aplicação do espírito geométrico aos assuntos humanos. A elegância da construção faz com que alguns considerem o sistema de Hobbes compatível com um estado imune à instabilidade. No entanto, o ceticismo bayleano opõe à pretensão sistemática, mais uma vez, o primado do contingente e do circunstancial:

...as idéias mais razoáveis estão sujeitas a milhares de inconveniências quando postas em prática; quando são feitas tentativas de implementá-las diante do assustador volume de emoções que impera entre a humanidade: não é nada dificil encontrar muitas falhas no sistema politico desse autor. ${ }^{34}$

Em sua passagem mais eloqüente, a denotar ceticismo diante da pretensão sistemática, Bayle nomeia os inimigos invencíveis de sistemas tais como os de Platão, More e Campanella: "as paixões humanas, que se alimentam umas às outras em prodigiosa variedade, imediatamente arruinarão as esperanças inspiradas por esses sistemas refinados". O mesmo se dá com os matemáticos, quando tentam aplicar ao mundo material suas "linhas e suas áreas". São as paixões humanas que derrotam o espírito matemático e a obsessão por sistemas. Desta forma, o veto ao espírito geométrico aproxima-nos do tema da condição humana. Ao atingir o tema antropológico, Bayle opõe Descartes a Hobbes. Aqui o que importa não é a denúncia das obsessões geométricas, mas as proposições hobbesianas a respeito da natureza humana. Segundo Descartes, pelas mãos de Bayle, os princípios de Hobbes são "extremamente perniciosos e muito perigosos", na medida em que apresentam os seres humanos como brutais e lhes dão razão para assim o ser. Diz ainda Descartes que o propósito

30 Cf. Pierre Bayle, "Hobbes”, In: Sally L. Jenkinson (Ed.), op. cit., pp. 79-92.

31 Ibidem, p.84.

32 Ibidem, p. 84.

33 Ibidem, p. 84.

34 Ibidem, pp. 84-85. 
hobbesiano de escrever a favor da causa monárquica poderia ser cumprido a partir de "máximas mais virtuosas e mais substanciais". Conclui por afirmar não ver como Hobbes poderia impedir que seu livro - De Cive - fosse censurado. ${ }^{35}$

Parte considerável do desacordo de Bayle pode ser atribuído ao fato de que, mais do que movido por um sistema geométrico, Hobbes pretende nele encerrar a idéia mesma de natureza, quer pela definição de uma lei natural, quer pela postulação de uma natureza humana universal. A natureza como fundamento opõe-se à variedade da experiência histórica, uma diversidade constituída por uma experiência passional acumulada. Em outros termos, a oposição mais fundamental de Bayle ao jusnaturalismo - e a mais especificamente cética, como sustenta Brahami ${ }^{36}$ - diz respeito às relações entre a suposição da natureza e a variedade histórica.

Para além dos limites do verbete Hobbes, Bayle externou por vezes uma concepção negativa da natureza humana. Na Continuation des Pensées Diverses o homem é "un fonds gatê et corrompu, et une terre maudite", ${ }^{37} \mathrm{em}$ um registro que sabe a Agostinho e aos jansenistas (e mesmo aos calvinistas). A natureza em geral, longe de ser uma norma, é uma patologia: "La nature est un état de maladie", segundo o texto das Réponses aux questions d'un provincial. ${ }^{38}$ Segue-se que as impressões da natureza não são critério nem de verdade epistemológica, nem de valor moral. Ao contrário de Hobbes, não é a história que deve ser ignorada, mas a natureza. A história humana se constrói fora e a jusante da natureza.

No mesmo texto, aparece como impossível a distinção no homem daquilo que decorre das impressões da natureza e daquilo que provém da educação. Não há um conceito inequívoco de natureza, suficientemente claro para produzir efeitos positivos tanto em política como em moral (para Bayle, não sabemos o que é natural em política e em moral).

Il n'y a guère de mot dont on serve d'une manière plus vague que celui de Nature. Il entre dans toutes sortes de discours tantôt en un autre, et on ne s'attache presque jamais à une idée precise. Mais quoi qu'il en soit, ceux qui philosophent exactement m'avoueront que pour être bien assurés q'une telle et une telle chose nous sont inspirées par la nature, il faudrat savoir que de jeunes gens le connaisent sans le secours d'aucune instruction. Je ne crois pas qu'on ait des expériences de ce qui se

35 Ibidem, pp. 85-86:.

36 Cf. Frédéric Brahami, "Théories Sceptiques de la Poliqiques: Montaigne et Bayle", In: Gianni Paganini (Ed.), The Return of Scepticism: From Hobbes and Descartes to Bayle, Dordrecht/Boston/London: Kluwer Academic Publishers, 2003, pp. 377-392.

37 Cf. Pierre Bayle, Continuation des Pensées Diverses , 23, apud Fréderic Brahami, op. cit., p. 380.

38 Cf. Pierre Bayle, Réponses aux questions d'un provincial, I, 105, apud Frédéric Brahami, op. cit. p. 381. 
passe dans l'esprit d'un homme, à qui n'ait rien appris. Si l'on avait fait élever um centain nombre d'enfants par des personnes, que se fussent contentes de les nourrir sans leur enseigner aucune chose, nous verrions de quoi la nature toute seule est capable, mais nous ne connaissons que des gens que l'on a sifflés dès le berceau, et à qui l'on a fait accroire tout ce que l'on a voulu. ${ }^{39}$

A idéia de natureza humana resta confusa e indistinta. Não podemos dizer o que resulta da natureza e o que é proveniente do artifício. Em Bayle seria impossível realizar o projeto de Rousseau, anunciado na Introdução ao Discurso sobre a Origem e os Fundamentos da Desigualdade entre os Homens: distinguir na conformação dos homens o que é natural e o que lhe foi acrescentado artificialmente. ${ }^{40}$

Os principais diferendos de Bayle para com Hobbes dizem respeito, pois, à pretensão de uma ciência da política e à postulação de uma natureza humana universal, cujos traços constituem-se como referência compulsória e racional para a configuração do Estado. No que diz respeito ao tema da soberania, esta parece ser algo que resulta antes da experiência do mundo do que da razão e do direito natural.

O saber da política em Bayle é antes uma téchne do que uma ciência more geométrico. Trata-se de uma ciência conjectural, tal como a medicina, suscetível ao acaso e ao imperativo das circunstâncias particulares. No que diz respeito à política, a ciência é substituída por uma arte que exige um senso agudo de singularidade, não suscetível de subordinação a um quadro regido por máximas abstratas.

\section{Dos erros de Bayle: Montesquieu}

Montesquieu, segundo Robert Schakleton, no início de sua carreira literária sofreu vigorosa influência de Bayle. ${ }^{41} \mathrm{O}$ primeiro registro pode ser encontrado na Dissertation sur la politique des Romains dans la religion, de 1716. $\mathrm{Na}$ abertura, Montesquieu reforça o tema da origem política das religiões: " $\mathrm{Ce}$ ne fut ni la crainte ni la pitié que établit la réligion chez les Romains, mais la necessite où sont toutes les sociétés d'en avoir une". ${ }^{22}$ Schakleton indica a afinidade entre a passagem e a seguinte, na abertura das Considérations des Pensées Diverses, na qual Bayle celebra os que deram origem aos Estados:

39 Cf. Pierre Bayle, Réponses aux questions d'un provincial, I, 105, apud Frédéric Brahami, op. cit. p. 381.

40 Cf. Jean-Jacques Rousseau, COMPLETAR

41 Cf. R. Shackleton, "Bayle and Montesquieu", In: Paul Dibon (Ed.), Pierre Bayle: le Philosophe de Rotterdam, Amsterdam/Paris: Elsevier/Vrin, 1959., pp. 142-149.

42 Apud R. Schakleton, op. cit., p. 143. 
"Leur soins ont civilisé les hommes sauvages, et leur ont donné un nouveau goût par l'introduction du culte des dieux", ${ }^{43}$

Há, contudo, objeções por parte de Montesquieu. Não mais o jovem autor da Dissertação, mas o autor do Espírito das Leis, em seu livro XXIV, nos capítulos 2 ("Paradoxo de Bayle") e 6 ("Outro paradoxo de Bayle"), indica dois erros cometidos pelo autor do Dicionário, a saber:

(i) Bayle pretendeu provar que valia mais ser ateu do que idólatra;

(ii) Bayle, depois de ter insultado todas as religiões, flagelou a religião cristã; ousou afirmar que verdadeiros cristãos não formariam um Estado que pudesse subsistir.

As objeções de Montesquieu dizem respeito a dois argumentos fundamentais de Bayle: o da da indistinção entre ateísmo e cristianismo no que diz respeito à moralidade e o da distinção entre conduta privada - i. e.,fixada no plano da crença individual - e seu efeito agregado, combinado com as demais condutas de outros agentes sociais.

Pelo primeiro argumento, Bayle sustenta não haver distinção básica entre uma sociedade de ateus e uma sociedade de cristãos, já que a motivação real dos homens - ateus ou cristãos - está contida nas "paixões que dominam no momento seu coração ... (e pela) inclinação natural por prazer". ${ }^{44}$ A origem das virtudes (inclinação à piedade, sobriedade, etc...) não depende da "suposição de um deus"...mas do "temperamento e da constituição particulares" (do agente), "fortalecidas pela educação, pela auto estima, pela vaidade, pelo instinto de razão....motivos que prevalecem tanto nos ateus como nos demais". ${ }^{45}$

$\mathrm{O}$ segundo argumento pode ser depreendido da seguinte passagem dos Pensées Diverses sur la Comète:

Os verdadeiros cristãos, parece-me, consideram-se a si mesmos como viajantes e peregrinos na direção do paraíso, seu verdadeiro país. Percebem o mundo como um exílio...estão...sempre dispostos a mortificar sua carne, a reprimir o amor por riquezas e honras, a reprimir os prazeres da carne e a subjugar o orgulho...

Examine bem isso e você concluirá, estou certo, que uma nação totalmente composta por pessoas desse tipo seria rapidamente escravizada se algum inimigo se dispusesse

43 Cf. Pierre Bayle, Continuations des Pensées Diverses, I, p. 22, apud R. Shackleton, op. cit. p. 144.

44 Cf. Pierre Bayle, Pensées Diverses sur le Comète, apud Thomas Horne, The Social Thought of Bernard Mandeville: Virtue and Commerce in Early Eigtheenth Century England, London: The Macmillan Press, 1979, p. 29.

45 Idem, p. 30. 
a conquista-la, porque seria incapaz de contar com bons soldado ou de dispor de dinheiro suficiente para pagar o custo dos mesmos. ${ }^{46}$

O que, afinal, a recepção de Montesquieu põe em relevo, na obra de Bayle? Tanto a recepção positiva quanto a negativa iluminam aspectos importantes da reflexão de Bayle. No primeiro caso, trata-se do desenvolvimento de uma abordagem civil e histórica do tema da religião. São os efeitos das crenças religiosas que parecem importar, em uma chave que considera a sua produtividade social. Há mesmo aqui a emergência de um argumento de corte teológico-político, pelo qual a religião importa como parte do ordenamento político.

A recepção negativa diz do desconforto de Montesquieu com duas teorias bayleanas que, para além do conteúdo específico de cada uma delas, indicam a presença na configuração do mundo histórico e social de mecanismos de indeterminação. Tais mecanismos devem-se ao fato de que é impossível derivar de uma profissão de fé religiosa a natureza do comportamento moral do agente, fato que aproxima o ateu do crente. Não é sua crença que determina seu modo de estar no mundo, mas um complexo causal no qual se mesclam, de forma não antecipável, aspectos não-reflexivos (passionais), algumas crenças e artifícios culturais (educação). O sentido geral do experimento social não é, pois, antecipável, dada a ação imparável de uma miríade confusa de seres humanos.

\section{4. Ênfases Finais}

1. A imagem sugerida por Bayle a respeito da ordem social revela um cenário no qual opera uma descontinuidade entre as imagens e representações que os indivíduos fazem de si mesmos e de seus propósitos no mundo e o resultado agregado de suas ações. O que se apresenta é um abismo das combinações, um resultado não antecipado das interações humanas. ${ }^{47}$

2. A observação atenta de Maquiavel aos exemplos e fatos da história e a renúncia à ciência more geométrico, por meio do comentário a Hobbes, parecem corresponder a um espírito de open-endedness que preside a compreensão bayleana do experimento humano. Tal princípio, mencionado por Thomas Lennon, ata em mesmo movimento a forma narrativa Bayle e 
a forma do mundo Bayle. Um dos legados de Bayle para o século XVIII - e para depois - foi o do desafio de compreender a vida social como algo que não resulta de finalidades ontológica e racionalmente pré-estabelecidas.

3. Não é mais o caso de falar no enigma Bayle, e sim no problema Bayle, no que diz respeito ao entendimento dos modos de configuração da vida social. Um problema que envolve uma concepção aberta e não-finalista da história e uma forma própria de considerar o tema da crença. Há, em Bayle, um esforço de distinção entre a crença como (i) doutrina dogmática e compreensiva, como pretensão de atribuição completa de sentido ao mundo, e como (ii) um operador infinitesimal, como domínio da pequena crença - de algo assemelhado ao local knowledge geertziano - que, a despeito de seu alcance imediato, produz, no agregado, efeitos independentes e não antecipados. Por vezes tal micro-domínio aparece subsumido em um campo puramente passional e não-reflexivo.

4. Nesse sentido, a crença é sempre local - em mais uma aparição da sombra do tropo das circunstâncias, cláusula pétrea do ceticismo. Um mistério, portanto, se inscreve na própria fábrica do social: como explicar o nexo daquilo que provém de uma miríade de situações e crenças locais e acaba por configurar um efeito agregado e não-antecipado? Está posto o desafio para uma teoria cética da causalidade, que consiste em observar e relatar a relação entre ação humana e seus resultados, sem qualquer ajuda do aristotelismo (hipótese teleológica) ou de qualquer decantação providencial da razão na história (jusnaturalismo).

\section{Bibliografia citada}

BAYLE, Pierre. “Bodin”, In: S. Jenkinson (Ed.), Bayle: Political Writings, Cambridge: Cambridge University Press, 2000.

"Hobbes", In: S. Jenkinson (Ed.), Bayle: Political Writings, Cambridge: Cambridge University Press, 2000.

. "Machiavelli", In: S. Jenkinson (Ed.), Bayle: Political Writings, Cambridge: Cambridge University Press, 2000.

BRAHAMI, Fréderic. "Théories Scpetiques de la Politique: Montaigne et Bayle", In: Gianni Paganini (Ed.), The Return of Scepticism: From Hobbes and Descartes to Bayle, Dordrecht/Boston/London: Kluver Academic Publishers, 2003.

FERGUSON, Adam. An Essay on the History of Civil Society, Cambridge: Cambridge University Press, 1996.

GIL, Fernando. A Convicção, Porto: Campo das Letras, 2003

GIOCANTI, Silvia. Penser l'Irrésolution: Montaigne, Pascal, La Mothe Le Vayer. Trois itinéraires sceptiques, Paris, Honoré Champion, 2001. 
HORNE, Thomas. The Social Thoght of Bernard Mandeville: Virtue and Commerce in Early Century England, London: The Macmillan Press, 1979.

HUME, David. Investigação sobre os princípios da moral, Campinas: Editora da Unicamp, 1995.

Tratado da Natureza Humana, São Paulo: Editora da Unesp, 2009.

JENKINSON, Sally (Ed.). Bayle: Political Writings, Cambridge: Cambridge University Press, 2000.

LENNON, Thomas. Reading Bayle, Toronto: University of Toronto Press, 1999

LABROUSSE, Elisabeth. Pierre Bayle, Paris: Albin Michel, 1996.

LESSA, Renato. Veneno Pirrônico: ensaios sobre o ceticismo, Rio de Janeiro: Francisco Alves, 1997.

"Montaigne's and Bayle's Variations: The Philosophical Form of

Scepticism in Politics", In: J. R: Maia Neto, J. G: Laursen and G. Paganini (Eds.), Skepticism in Modern Age: Building on the worko of Richard Popkin, Leiden: Brill, 2009.

MAIA NETO, José Raimundo. “O ceticismo de Bayle”. Kriterion, 93, 1995.

MANDEVILLE, Bernard. The Fable of the Bees or Private Vices, Publick Benefits, Indianapolis: Liberty Fund, 1988.

PIRES AURÉLIO, Diogo. A vontade de sistema: estudos sobre filosofia e politica, Lisboa: Cosmos, 1998

POPKIN, Richard. "Pierre Baye's place in the $17^{\text {th }}$ century", In: Paul Dibon (ed.), Pierre Bayle: le Philosophe de Rotterdam, Amsterdam/Paris: Elsevier/Vrin, 1959. SCHAKLETON, Robert. "Bayle and Montesquieu", In: Paul Dibon (ed.), Pierre Bayle: le Philosophe de Rotterdam, Amsterdam/Paris: Elsevier/Vrin, 1959.

SEXTUS EMPIRICUS. Outlines of Pyrrhonism (Ed. R. Bury), Buffalo, NY: Prometheus Books, 1990.

WHELAN, Ruth. The Anatomy of Superstition: A Study of the Historical Theory and Practice of Pierre Bayle, Oxford: Oxford University Press, 1989 